\title{
Mass customisation as a collaborative engineering effort
}

\section{Songlin Chen*, Yue Wang and Mitchell M. Tseng}

Advanced Manufacturing Institute, The Hong Kong University of Science and Technology, Clear Water Bay, Hong Kong

Fax: 85223580191

E-mail: songlin@ust.hk

E-mail: yacewang@ust.hk

E-mail: tseng@ust.hk

${ }^{*}$ Corresponding author

\begin{abstract}
Mass customisation aims to deliver customised products with near-mass production efficiency. To simultaneously achieve customisation and efficiency, mass customisation requires collaborative engineering efforts between customers and manufacturers, who usually have different preferences concerning customisation. Collaborative engineering offers new methodologies and tools to address some of the inherent conflicts in mass customisation; reciprocally, mass customisation offers a realistic and promising test bed for developing collaborative engineering theories and technologies. This paper explores the synergies between these two fields of study, sketches out the scenarios of applying collaborative engineering in mass customisation, and points out some directions for future research.
\end{abstract}

Keywords: mass customisation; collaborative engineering; synergy.

Reference to this paper should be made as follows: Chen, S., Wang, Y. and Tseng, M.M. (2009) 'Mass customisation as a collaborative engineering effort', Int. J. Collaborative Engineering, Vol. 1, Nos. 1/2, pp.152-167.

Biographical notes: Songlin Chen is currently a $\mathrm{PhD}$ candidate in the Department of Industrial Engineering and Logistics Management at the Hong Kong University of Science and Technology (HKUST). His research interest is focused on negotiation and auction theory and its application in mass customisation, engineering design, and supply chain collaboration. He holds a Bachelor's Degree, 2001, in Aerospace Engineering from the National University of Defence Technology in China and a Master's Degree, 2003, in Aeronautics and Astronautics from Stanford University in USA.

Yue Wang received both his Bachelor and Master Degrees in Electronic Engineering from Peking University, China. He is currently a $\mathrm{PhD}$ candidate in the Department of Industrial Engineering and Logistics Management at the HKUST. His research interest is focused on mass customisation and product configuration system, artificial intelligence and its application in engineering design and manufacturing, etc.

Mitchell M. Tseng is Chair Professor and Director, Advanced Manufacturing Institute of HKUST. He joined HKUST as the Founding Department Head of Industrial Engineering in 1993 after working in industry for two decades. 
He held executive positions at Xerox and Digital Equipment Corporation as well as faculty positions at University of Illinois at Champaign-Urbana and Massachusetts Institute of Technology. He is an elected fellow of the International Academy of Production Engineers (CIRP) and American Society of Mechanical Engineers (ASME). He is widely recognised for his work in mass customisation and global manufacturing.

\section{Introduction}

Mass customisation aims to deliver products and services that best meet individual customers' needs with near-mass production efficiency (Tseng and Jiao, 1996). It is a production paradigm that tries to combine the benefits of craft production of pre-industrial economies and mass production of the industrial economies. The paradigm shift to mass customisation is made an imperative for many companies to effectively compete in an increasingly diversified, fragmented, and competitive marketplace; it is made possible by the revolutionary progress in technologies like information technology, flexible manufacturing systems, fast prototyping, etc. (Pine et al., 1993; Pine, 1993; Kotha, 1995).

Mass customisation has attracted enormous attention from both academia and industry in the last two decades (Silveria et al., 2001; Tseng and Piller, 2003) and has been widely recognised as a viable strategy for companies to gain competitive advantage. Bain \& Company (2005), a management consulting powerhouse, has included mass customisation in its annual survey of management tools and trends that have strategic importance. Currently, the focus of research in mass customisation is shifting from its strategic viability to operational feasibility, i.e., from questions on what and why to how (McCarthy, 2004). Many firms like Dell, Motorola, Hewlett-Packard, Adidas are experimenting or implementing mass customisation as a new manufacturing strategy. According to Selladurai (2004), mass customisation is no longer an oxymoron but a reality.

Despite its advances in academia and industry, mass customisation continues to be challenged by critics as well as reality from all sorts of aspects. Companies implementing mass customisation often find themselves mired in a net of conflicts both strategically and operationally. For example, McCutcheon et al. (1994) discuss the conflict between customisation and responsiveness, which is often cited as a key roadblock to achieve mass customisation; Squire et al. (2006) conduct empirical studies and demonstrate the existence of conflict between customisation and manufacturing cost; Agrawal et al. (2001) and Zipkin (2001) assert that mass customisation is only viable for a very limited range of applications; Spring and Dalrymple (2000) conclude similarly that mass customisation has limited novelty and restricted applicability.

Essentially, these challenges and conflicts can be traced to information asymmetry and preferential conflicts between customers and manufactures in customisation. According to Von Hippel (2005), customers and manufacturers are asymmetrically endowed with need information and solution information, respectively. Both types of information are 'sticky' in the sense that they are difficult to be acquired, transferred, and used in a different location. Innovative tactics and technologies like differentiation postponement (Feitzinger and Lee, 1997), product family design (Tseng and Jiao, 1996), 
and product configuration systems (Salvador and Forza, 2004) have greatly mitigated the severity of these challenges. But, the ever-escalating market competition and customer expectation keep pushing firms to the edge and there is a genuine need for more effective means for customer-manufacturer collaboration in general (conflict resolution in particular) so as to move mass customisation forward.

Emerging research in collaborative engineering, particularly the emerging Engineering Collaboration via Negotiation (ECN) as proposed by Lu (2003), promises great potential to tame many of the challenges that are currently constraining many mass customisation programmes. From a collaborative engineering perspective, mass customisation can be viewed as a series of activities, many of which are of engineering nature, where customers and manufacturers with different preferences engage in interactive problem solving and joint conflict resolution to create artefacts that best satisfy individual customers' needs while simultaneously meet manufacturers' economic objectives. Viewing mass customisation from collaborative engineering perspective offers a new angle to advance mass customisation research and implementation; reciprocally, the vested interests of different players in mass customisation offer a realistic and promising test bed for developing collaborative engineering theories, technologies, and tools.

This paper aims to explore the synergies between mass customisation and collaborative engineering. The first part introduces mass customisation concept, its historical development, and then examines the challenges and conflicts that are currently constraining its implementation. In the second part, research in collaborative engineering is introduced as a potential conceptual framework to address the challenges and conflicts associated with mass customisation. In the third part, a generic framework of mass customisation is introduced. Based on the framework, potential scenarios of applying collaborative engineering in mass customisation are characterised, and the potential use of mass customisation as a test bed for collaborative engineering research is discussed.

\section{Mass customisation as a new production paradigm}

\subsection{Mass customisation concept}

The concept of mass customisation was first expressed in Toffler's book Future Shock, in which he predicted that future manufacturing enabled by information technology would be able to provide customised products in a large scale with little or no extra cost (Toffler, 1970). The term 'mass customisation' was first coined by Davis (1987) in his book Future Perfect, in which he described a trend where companies sought to micro-segment markets and offer unique products and services to customers. It is Pine et al.'s Harvard Business Review paper (Pine et al., 1993) and Pine's book (Pine, 1993) that popularised the concept of mass customisation and ignited a wave of academic research and industrial experimentation. In their work, mass customisation was defined as the ability to provide individually designed products and services to every customer through high process agility, flexibility, and integration.

Many authors propose more practical definitions by describing mass customisation as a system that uses information technology, flexible processes, and organisational structures to deliver a wide range of products and services that meet specific needs of 
individual customers at a cost near that of mass-produced items (e.g., Hart, 1995; Tseng and Jiao, 1996; Silveria et al., 2001). In general, mass customisation can be described as a production paradigm that tries to combine the benefits of craft production of pre-industrial economies and mass production of the industrial economies, aiming to deliver products and services that best meet individual customers' needs with near-mass production efficiency.

It is worth noting that mass customisation is not equivalent to mass production with batch size of one. Instead, mass customisation is fundamentally different from mass production and requires different values and roles, systems, learning methods, and ways of relating to customers (Pine et al., 1993; Pine, 1993; Kotha, 1995; Piller et al., 2004). One essential feature that differentiates mass customisation from mass production is that customers are actively involved in the value creation process in mass customisation (Duray, 2002; Piller et al., 2004). In mass production, customers are subjects to be observed, their demand is to be forecasted, and their attention and purchasing decisions are to be studied, influenced or even manipulated, as manufacturers strive to push their products into the market. In mass customisation, customers are no longer passive recipients of products or services that are designed and produced for a nominal customer. Instead, each customer has his or her individual identity and provides key inputs in designing, producing, and delivering the product or service based on his or her individual preferences. By synthesising relevant literature, Table 1 summarises the key differences between mass customisation and mass production.

Table 1 Mass customisation vs. mass production

\begin{tabular}{|c|c|c|}
\hline & Mass production & Mass customisation \\
\hline Goal & $\begin{array}{l}\text { Delivering goods and services at } \\
\text { prices low enough that nearly } \\
\text { everyone can afford them }\end{array}$ & $\begin{array}{l}\text { Delivering affordable goods and } \\
\text { services with enough variety and } \\
\text { customisation that nearly everyone } \\
\text { finds exactly what they want }\end{array}$ \\
\hline Economics & Economies of scale & $\begin{array}{l}\text { Economies of scope and customer } \\
\text { integration }\end{array}$ \\
\hline Focus & $\begin{array}{l}\text { Efficiency through stability and } \\
\text { control }\end{array}$ & $\begin{array}{l}\text { Variety and customisation through } \\
\text { flexibility and responsiveness }\end{array}$ \\
\hline Product & $\begin{array}{l}\text { Standardised products built to } \\
\text { inventory }\end{array}$ & $\begin{array}{l}\text { Standardised modules assembled based } \\
\text { on customer needs }\end{array}$ \\
\hline \multirow[t]{5}{*}{ Key features } & - $\quad$ Stable demand & - $\quad$ Fragmented demand \\
\hline & - $\quad$ Large homogeneous markets & - Heterogeneous niches \\
\hline & $\begin{array}{l}\text { Low-cost, consistent quality, } \\
\text { standardised goods and } \\
\text { services }\end{array}$ & $\begin{array}{l}\text { Low-cost, high-quality, } \\
\text { customised goods and services }\end{array}$ \\
\hline & $\begin{array}{l}\text { - Long product development } \\
\text { cycles }\end{array}$ & - $\quad$ Short product development cycles \\
\hline & - Long product life cycles & - $\quad$ Short product life cycles \\
\hline Organisation & Mechanistic and hierarchical & Organic and flexible \\
\hline $\begin{array}{l}\text { Customer } \\
\text { involvement }\end{array}$ & $\begin{array}{l}\text { Customers are passively involved } \\
\text { in the value chain }\end{array}$ & $\begin{array}{l}\text { Customers are actively integrated into } \\
\text { the value chain }\end{array}$ \\
\hline
\end{tabular}




\subsection{Development of mass customisation}

The concept of mass customisation originated in a historical context where mass production as the predominant production paradigm since Henry Ford ran into crisis in a new market reality and technology landscape. The paradigm shift to mass customisation is mainly propelled by three forces. The first is market demand. An increasingly affluent society and diversifying demographic characteristics demand products and services that are tailored to individual customers' specific needs. Kotler (1989) claims that "the mass market is dead and segmentation has progressed to the era of mass customisation". $\mathrm{He}$ argues that there is an increasing demand for product variety and customisation, and even segmented markets are too broad, as they no longer permit developing niche strategies.

The second force is market competition. As customers become increasingly empowered and globalisation gains momentum, companies across many industries are faced with local rivals as well as competition from abroad. Product variety is exploding while product life cycle is shortening. As a result, many companies operating under the mass production doctrine of economies of scale find it increasingly difficult to amass enough volume, effectively differentiate from competition, accurately forecast demand or plan production. Many manufacturing firms are operating with more frequent orders, but with smaller volume of each order.

The third is technological revolutions, which enable new ways of organising production activities and doing business in general. Flexible manufacturing systems allow manufacturers to quickly adapt to changes in product variety, volume, and delivery schedule without incurring high penalty in terms of cost and lead time. Information technologies like internet and telecommunication systems establish efficient channels for companies to reach widely dispersed population and in the meanwhile interact directly with each individual customer.

Since the birth of the mass customisation concept, many companies and entrepreneurs have been striving to implement mass customisation for competitive advantage. Some of these initiatives were very successful. One of the most cited cases is Dell Computer, which is able to deliver customised personal computers and notebooks within one week with prices lower than its mass producing competitors. By adopting mass customisation, Dell Computer has gained the so-called first-mover advantage and maintained high profitability and growth in a hyper-competitive industry for a long period (Magretta, 1998). Other prominent cases include Motorola's customised pagers, Adidas Mi customised shoes, Hewlett Packard's printers, etc. (Feitzinger and Lee, 1997; Selladurai, 2004).

\subsection{Economics of mass customisation}

From a customer's point of view, the economic justification of mass customisation lies in the availability of more choices that could potentially best fulfil the customer's individual-specific needs with slightly or no extra payment. However, there are some mediating factors. First, choice itself does not mean value but only a potential. Choices are associated with tradeoffs, which may not be a pleasant experience to customers and could result in dissatisfaction or even distress (Schwartz, 2004). Huffman and Kahn (1998) points out that there is a thin line between mass customisation and mass confusion. Second, customers may not know what they really want. Need is a term with 
contextual connotations. It is subject to influences of the social environment, human emotions, and other factors that are difficult to be captured. Customers are often unable to articulate their needs for a customised product. Third, there is an asymmetry between customers and manufacturers in terms of information and knowledge. Customers may fail to understand or appreciate manufacturers' offerings even when the customised offer fulfils their articulated preferences (Simonson, 2005).

From the manufacturers' point of view, the economic justification lies in the notion of 'economies of integration'. According to Piller et al. (2004), with customers integrated into value creation in the customisation process, companies gain access to more accurate information about market demand and can postpone some activities until an order is placed. As a result, manufacturers can reduce, if not eliminate, expensive inventory of finished goods. Also, by producing in response to real market demand, manufacturers can avoid using costly marketing techniques like sales discounts to clear unpopular products. In a highly competitive and volatile marketplace, the cost of inaccurate forecast could be very significant. Furthermore, customer loyalty can be enhanced via customisation because companies are able to interact with each individual customer directly. The information gained through customer interaction also provides valuable insight into customers' latent needs and can guide future product development (Kotha, 1996; Piller et al., 2004).

In general, the key issue in mass customisation from an economic perspective is how to leverage economies of integration to compensate potential loss of economies of scale and provide individual customer's choices that can best satisfy their specific needs with superior experiences. More specifically, this translates into finding an effective means to best match customers' individual specific needs with manufacturers' customisation capabilities.

\subsection{Conflicts in mass customisation}

Despite recent advancement in both theoretical development and technology progress, it is still a daunting task for companies to successfully implement mass customisation. Many mass customisation programmes were folded and large amounts of investment had to be written off. Some pioneering companies, e.g., Levi's Strauss and P\&G, have retreated from their mass customisation initiatives. ${ }^{1}$ Toyota learned the hard way that mass customisation requires very different organisational structures, values, management roles and systems, and customer relations, which Toyota, the most successful car manufacture in the world, was not ready yet. In general, mass customisation is not the natural next-stage of mass production via incremental change. Instead, it is a system-wise overhaul of traditional paradigm of organising production and doing business. It challenges the traditional taboo of combining mass with customisation, while in the meantime it submerges itself into a flood of conflicts that need to be carefully handled.

Strategically, there is an inherent conflict within mass customisation as its name suggests and as many critics rightly claim: Mass implies aggregation and repetition, while customisation means individual and one-of-a-kind. Traditionally, companies compete either on mass via high efficiency and low cost or on customisation by offering differentiated solutions and charging monopoly premiums. Combining mass and customisation into a single strategy risks saddling the company in a dilemma where competitive advantage gets lost on both ends. Operationally, there are conflicts between different performance objectives in mass customisation. Under the customer-centric 
philosophy, customers' pull is the ultimate driving force for mass customisation (Tseng and Piller, 2003). However, customers' needs are usually diverse and irregular. The diversity of customer needs requires manufactures to offer high product variety, which often leads to high component variety, large numbers of suppliers, and high administrative complexity. The irregularity of individual customers' needs means demand unpredictability and instability. As a result, production planning becomes very difficult and ineffective, leading to either resource under-utilisation or shortage. Furthermore, as the value chain in product customisation is driven by customers' 'pull' instead of manufacturers' 'push', delivery lead time becomes part of customers' waiting time. Customers' increasing demand for responsiveness further aggravates the difficulty to simultaneously achieve high efficiency and high quality of customisation.

Although conflicts abound and usually assume different forms, ultimately they can be accounted for by the opposing preferences between manufacturers and individual customers, both of whom have to make trade-offs in seeking of a customised solution with superior value propositions. With customers actively integrated into product customisation, tradeoff-making needs to be done in a collaborative way so that customers' needs could be well matched with manufacturers' capabilities. One critical issue in mass customisation is how manufacturers and individual customers could work collaboratively and resolve conflicts effectively for mutual benefits.

\section{Collaborative engineering as a tool for conflict resolution}

To collaborate means, "to work jointly with others or together, especially in an intellectual endeavor" (Merriam-Webster dictionary). How to collaborate effectively has been a subject of research since the birth of human beings. Recent development in information technology like internet and telecommunications has enabled people to engage in collaboration 'virtually' across temporal and geographical boundaries. To date, researchers from various disciplines including optimisation, group decision-making, business research, and computer science have employed different methodologies and techniques to study the general subject of collaboration, and collaborative engineering in particular (Lu, 2003).

According to Monplaisir and Salhieh (2002), collaborative engineering can be viewed as a process in which people working in teams according to engineering methodologies and supported by technical tools can share resources and knowledge to achieve common goals. The italic words are the key elements in collaborative engineering. More specifically, people are the main body of collaborative engineering since all enterprises and organisations are made up of people, no matter they are physically co-located or virtually co-located. Engineering methodologies include methodologies like Quality Function Deployment (QFD), Concurrent Engineering, etc., which basically prescribe a systematic framework and process to conduct collaboration activities. The technical tools are supporting systems that can be utilised to facilitate collaboration process.

A key issue in collaborative engineering is how to resolve conflicts, since participants' preferences are often not fully aligned and there is uncertainty involved. Recently, Lu (2003) proposes ECN as a new paradigm for collaborative engineering. $\mathrm{ECN}$ is defined as 
"a socio-technical decision making activity where a team of stakeholders with
different expertise and mixed motives engage in interactive and joint conflict
resolutions to co-construct consensual agreements of some engineering matter."

The ECN framework treats collaborative engineering as a socially mediated technical activity, which concerns more about human behaviour and its impact on technical decisions. It also treats the collaborative engineering as a dynamical system in which each participant's views may change and be influenced by others' perspectives, i.e., a process of negotiation.

\section{Mass customisation in collaborative engineering perspective}

\subsection{Conceptual synthesis}

Viewed from collaborative engineering perspective, mass customisation is essentially a production paradigm under which customers and manufacturers collaboratively create products or services to best meet individual customers' needs in an efficient way. The process of product or service creation is essentially of engineering nature but also has a social bearing because of the interactions among engineers, sales, marketing, etc. Conceptually, mass customisation can be taken as a collaborative engineering activity, where customers and manufacturers with asymmetric information and different preferences engage in interactive and joint conflict resolutions to co-create an artefact. How such collaboration can be carried out effectively and efficiently is an ideal research topic for collaborative engineering, and it also holds a key to advance mass customisation research and implementation. In general, there are synergies between these two fields of study. On the one hand, collaborative engineering research results can be applied to address various collaboration issues in mass customisation; on the other hand, mass customisation offers a fertile test bed to develop new collaborative engineering theories, techniques, and tools.

\subsection{Applying collaborative engineering in mass customisation}

Firms pursue mass customisation following different routes; customers get involved at different points along the value chain and they are involved in different ways subject to factors like industry structure, product nature, market conditions, etc. Different operation modes of mass customisation will involve different people and require different approaches and methodologies for collaboration. This section refers to a generic mass customisation framework to discuss where and how collaborative engineering could be applied in mass customisation.

In discussing product customisation in a broad manufacturing strategy context, Spring and Dalrymple (2000) propose a generic model of product customisation, which includes three stages, namely problem solving, design specification, and transfer (Figure 1). The problem-solving stage can be further decomposed to problem definition and solution realisation. During the problem-solving stage, the product customisation concept and design scheme are determined and agreed between customers and manufacturers. Design specification follows problem solving and it is the stage where a particular customisation type or product configuration is determined based on the product architecture. The design specification and the process by which it is achieved will 
determine the firm's performance on some of the operational objectives, e.g., quality, service and cost. The transfer stage is to convert design specifications into actual products.

Figure 1 A model of product customisation

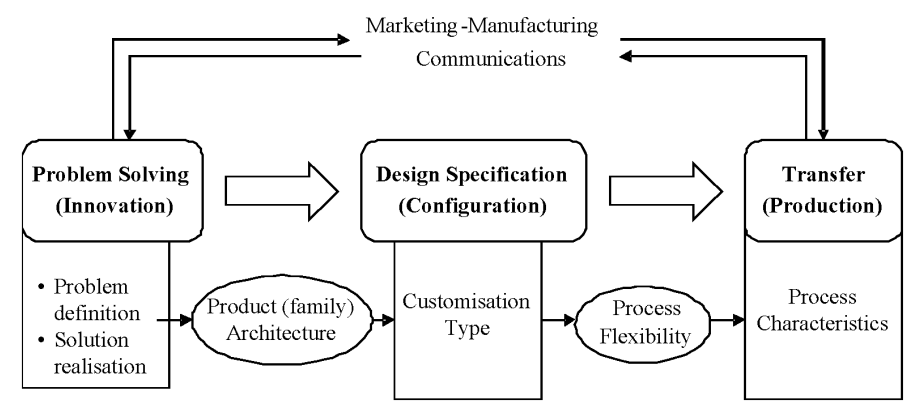

Source: Adapted from Spring and Dalrymple (2000)

The three-stage model provides a generic and compact framework to conceptually approach mass customisation. A limitation is that customer-manufacturer interaction is confined to the problem-solving stage only. This paper extends this model to allow customer integration in design specification and transfer stages as well and uses the extended model as a framework to discuss the application scenarios of collaborative engineering in mass customisation. In correspondence to the three stages of customisation, these general scenarios are termed as co-innovation, co-configuration, and co-production, respectively. Relevant research is reviewed and discussed in more detail according to people/team, engineering methodologies, and tools within a collaborative engineering perspective (Figure 2).

Figure 2 Application scenarios of collaborative engineering in mass customisation

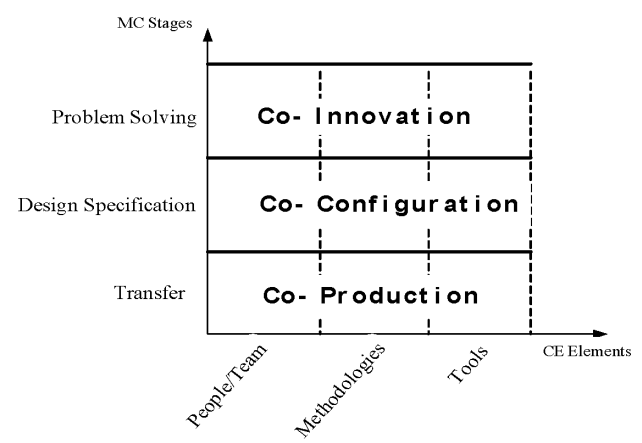

\subsubsection{Scenario I: co-innovation}

Mass customisation is a very dynamic system in the sense that both customers' needs and manufacturers' capabilities are constantly evolving. Given the diversity, irregularity, and unpredictability of customers' needs, it often happens that some customer may not find a satisfactory configuration out of the manufacturer's current offerings. As a result, companies implementing mass customisation are often challenged to design and develop 
new solutions, i.e., to innovate. The ability to innovate and innovate at a rate that matches or exceeds customers' changing tastes and expectations is critical for any mass customisation programme to sustain.

The source of innovation has been a subject of debate. The manufacturer-centric view holds that innovations result from intentional research, e.g., the design and development work in a company's R\&D centre. The user-centric (or customer-centric) view contents that many innovations actually come from users, particularly the so-called lead users, whose present needs will become general in a marketplace in the future (Von Hippel, 2005). One common foundation between these two different views is that (customers') need information and (manufacturers') solution information need to be brought together for innovation to take place. As a result, problem solving in mass customisation is collaborative in nature and designated as collaborative innovation (co-innovation) in this paper.

In a typically organisational setting, co-innovation usually takes place between customers and product or process design engineers, intermediated by sales, application engineers, marketing, etc. Customers could be individual consumers or business customers. If it is the latter, they are usually from the purchasing and sometimes engineering department. Among customers, the so-called lead-users deserve special attention. According to Von Hippel (2005), lead users are those users (or customers) who are ahead of the majority of users in their populations with respect to an important market trend.

As engineering methodology is concerned, the joint problem solving in mass customisation is essentially a collaborative design activity. Product Family Architecture (PFA) provides a compact and structured way to represent and organise design knowledge from multiple views (Tseng and Jiao, 1996; Jiao, 1998). Under PFA, customers, product engineers, and process engineers can work under a unified framework. As a result, PFA could serve as a framework for co-innovation. Given the preferential differences between customers and manufacturers, conflict resolution mechanism is a key issue in co-innovation. The ECN paradigm ( $\mathrm{Lu}, 2003)$ provides a promising methodology to address this issue.

For technical tools, engineering design tools like Computer Supported Collaborative Work (CSCW) (Monplaisir and Salhieh, 2002) can be used to support the co-innovation process. In the context of mass customisation, Von Hippel (2005) proposes user toolkits to facilitate user innovation. With the support of embedded design knowledge, customers are able to innovate on their own and design products or services according to their individual specific needs. Reversely, manufacturers can economise upon the cost of eliciting customers' 'sticky' need information by shifting partial design task to customers via user-friendly design tools. Future research is needed to understand customers' decision-making behaviour and the source of innovation during customer-manufacturer collaboration, develop new mechanisms and processes for co-innovation (e.g., collaboration via negotiation), design and develop new technical tools (e.g., interactive user toolkits) to facilitate the process of co-innovation.

\subsubsection{Scenario II: co-configuration}

Configuration is the stage where customers and manufacturers come to agree upon the specifications of a specific product offering. It corresponds to the design specification stage as defined by Spring and Dalrymple (2000) (Figure 1). Configuration is essentially 
a special form of product design with the PFA already defined and the solution space determined. In other words, configuration is a process of searching from a fixed pool of alternatives to locate a specific product variant that is mutually satisfactory to the customer and the manufacturer. The quality of configuration is critical to customer satisfaction because it will determine how well individual needs will be satisfied, and it also determines to a large extent on manufacturers' performance on several dimensions that include cost, delivery lead time, etc. However, high-quality configurations are usually difficult to achieve, particularly when the product to be customised is complex. It requires good understanding of customers' needs as well as manufacturers' offerings plus the ability to effectively match these two. However, good sales persons with deep technical knowledge are often a scarce resource.

One approach of configuration is to shift the task of configuration to customers via product configuration systems, e.g., Dell's online PC configurator. Using configurators can streamline the configuration process, reduce configuration errors, and enhance flexibility and responsiveness (Sabin and Weigel, 1998). However, shifting configuration to customers has its downside. When products are complex and customers are unclear about what they really want, they could get overwhelmed by the choices offered and the tradeoffs to be made. They may find the configuration process unpleasant or even stressful (Huffman and Kahn, 1998; Schwartz, 2004). Salvador and Forza (2004) did an extensive survey on the application of configurators for product customisation. Their findings indicate that although many companies tend to rely on product configuration systems to customise their products, they are faced with difficulties like inadequate product information supply to the sales office, excess of repetitive activities within the technical office, and high rate of configuration errors in production, etc.

The difficulties faced by many product configurators can be accounted by the partisan approach they take, i.e., they view configuration either from the manufacturer's or the customer's point of view while the collaborative nature of configuration in mass customisation is neglected. As a result, these configurators perform well in environment where manufacturers are able to effectively convey what they can provide or customers know precisely what they want. There is a need to treat configuration from a collaboration perspective to deal with the customer diversity and product complexity in mass customisation. We define the scenario of applying collaborative engineering in the design specification stage of mass customisation as collaborative configuration (co-configuration).

In a typical organisation setting, co-configuration often involves customers and sales engineers (sometimes design engineers). Up to date, there has been no engineering methodology developed specifically for co-configuration. Existing configuration design methodologies can be generally classified into rule-based, case-based, and model-based, depending on the reasoning techniques used (Sabin and Weigel, 1998). In a rule-based system, design knowledge is codified as configuration rules or constraints; in a model-based system, design knowledge is contained in a system model, which consists of decomposable entities and interactions between their elements; in a case-based system, new configurations are adapted from previous, similar configurations (or cases).

In recent development, Guttman and Maes (1999) propose Distributed Constraint Satisfaction as a new mechanism to support integrative negotiation with customers. Stolze and Strobel (2004) propose personal recommendation systems to facilitate customers in product configuration. Enabled by techniques like data mining, recommendation systems are able to suggest product variants based on customers' 
historical purchasing behaviours. However, this approach requires customers' needs and preferences to be relatively stable so that the preferences revealed in the past can have predictive power for future preferences. Further research is needed to better understand the dynamics within the co-configuration process, to develop engineering methodologies specifically for co-configuration. In the meantime, technical tools need to be developed to enrich the functionalities of existing product configurators and recommendation systems by enabling interactivity.

\subsubsection{Scenario III: co-production}

Production here corresponds to the transfer stage (Spring and Dalrymple, 2000) by including material conversion, material transportation, shop floor control, procurement, inventory management, etc. To many manufacturers, inefficiencies in production remain a critical roadblock to pursue mass customisation strategy. The simultaneous need for high variety, responsiveness, low cost, and high flexibility outstrips many manufacturers' financial resources or technical capabilities. Collaborating with supply chain partners or end customers promises great potential to further increase production efficiency, improve responsiveness, and reduce cost. We define the collaboration between customers and manufacturers in production functions of mass customisation as collaborative production (co-production).

The people involved in co-production usually include customers, supply chain managers, and production engineers, etc. By sharing demand and supply information, supply chain partners can better utilise production resources in response to volatile market demand. Many methodologies have been proposed for co-production from different perspectives. Cachon (2003) applies game theory to mathematically analyse different collaboration scenarios in a supply chain structure and design contracting schemes accordingly. The Voluntary Inter-industry Commerce Standards (VICS) group promotes Collaborative Planning, Forecasting and Replenishment (CPFR) as a roadmap to cope with mutual reconciliation of activities in supply chain collaboration (VICS, 2002). Advanced Planning Systems (APS) begin to incorporate collaborative planning as an important functionality (Kilger and Reuter, 2005).

$\mathrm{Up}$ to now, the scope of research on co-production has been focused at the supply chain level with business customers, and attention has been primarily placed on the value of information sharing. Primary methodologies are based on game theory and optimisation. Participants of collaboration are usually assumed to be utility or profit maximising. To cater to a mass customisation environment, there is a need to extend the research scope to investigate how manufactures and a large number of individual customers can collaboratively arrange production activities. The actual process of collaboration among participants with different agenda and local incentives also needs to be studied. Existing tools need to be interconnected, to enable interoperability and support effective conflict resolution.

Table 2 summarises the application scenarios of collaborative engineering in mass customisation. It is worth noting that the list in the table is not meant to be exhaustive or definitive but assumes a typical setting and serves as examples. Also, the boundaries between these general scenarios are not clear-cut. The decisions made during co-innovation will have their impact felt in co-configuration and co-production, and vice versa. So, it is important to apply collaborative thinking from the overall system perspective. 
Table 2 Application SCENARIOS of CE in MC

\begin{tabular}{llll}
\hline MC stages & People/team & Methodologies & Tools \\
\hline Co-innovation & Lead users & User innovation & Design toolkits \\
& $\begin{array}{l}\text { Design engineers } \\
\text { Process engineers }\end{array}$ & Product family architecture & CSCW \\
& ECN & \\
Co-configuration & Customers & $\begin{array}{l}\text { Rule-, model-, case-based } \\
\text { reasoning }\end{array}$ & Configurators \\
& Sales engineers & $\begin{array}{l}\text { Distributed constraint } \\
\text { satisfaction }\end{array}$ & $\begin{array}{l}\text { Recommendation } \\
\text { systems } \\
\end{array}$ \\
& Customers & CPFR & $\begin{array}{l}\text { Advanced planning } \\
\text { systems }\end{array}$ \\
& Supply chain & Contracting (game theory) & \\
& managers & & \\
& Production engineers & & \\
\hline
\end{tabular}

\subsection{Advancing collaborative engineering via mass customisation}

Based on the discussion in previous sections, collaborative engineering has wide applications in mass customisation. Reciprocally, the vested interests of different players in mass customisation offer a realistic and promising test bed for developing new collaborative engineering theories, technologies, and tools. There is great need for more effective means of collaboration in mass customisation. More specifically, individual customers are actively integrated into the value chain in customisation, but there is a gap between customers and manufacturers in terms of domain knowledge and product-specific information, which create barriers for communication and joint problem solving. Furthermore, during the customisation process, customers' preferences are often not fully aligned with manufacturers' preferences. The diversity of individual customers' needs and preferences poses great challenges for effective conflict resolution. Last but not the least, the simultaneous need for high variety, responsiveness, and flexibility in mass customisation creates enormous tensions between different performance objectives and further aggravates the challenges for effective collaboration in mass customisation.

The move towards mass customisation challenges the existing methodologies and techniques in collaborative engineering. Generally speaking, existing research in collaborative engineering tends to focus on the technical aspects and the integrative part of collaboration, i.e., how to share and aggregate information and to optimise from a centralised point of view. Future research is needed to study the social aspects and the distributive side of collaboration, i.e., how collaboration is conducted in a social context and how conflicts could be jointly resolved with diversified preferences and incentives. Negotiation has been widely practised in social and business interactions, and it has been widely studied in social science disciplines that include economics and decision science, and recently in computer science. Application of negotiation theory in collaborative engineering promises great potential to develop innovative methodologies and tools to support customers and manufacturers in product customisation. 


\section{Conclusion}

Mass customisation defies the contradiction between mass and customisation and aims to deliver products and services that best meet individual customers' needs with near-mass production efficiency. A novel and ambitious concept as it is, mass customisation is also exposed to various conflicts, both strategically and operationally. Ultimately, these challenges and conflicts can be traced to asymmetric information and the opposing preferences between manufacturers and customers, who need to work collaboratively to create new design alternatives. Thus, economic value is created by offering additional customer satisfaction without significant sacrifice of efficiency in design or production. The innovation in developing new custom options is primarily a collaborative effort among participants of diverse sets of self-interests. Therefore, it is important that all parties concerned can engage in collaboration with sufficient trust where we believe that collaborative engineering can play a significant role. Collaborative engineering can be essential for customers, manufacturers, and suppliers with different information, expertise, motives, preferences, and agendas to engage in interactive and joint conflict resolution.

This paper explores the synergies between mass customisation and collaborative engineering. General scenarios of applying collaborative engineering in mass customisation (co-innovation, co-configuration, and co-production) are proposed based on a generic mass customisation framework and discussed in collaborative engineering perspective in terms of people/team, engineering methodologies, technical tools. Reciprocally, the potential use of mass customisation as a test bed for advancing collaborative engineering research is also discussed and future direction of research is pointed out. Based on these scenarios, this paper reviews relevant works across a wide spectrum of interdisciplinary research topics. It appears that there is a mutually reinforcing linkage between mass customisation and collaborative engineering. There is great potential for interdisciplinary research towards creating new methodologies and tools to advance both fields of study.

\section{Acknowledgements}

This research is supported by National Natural Science Foundation of China (NSFC: No. 70418013) and Hong Kong Research Grants Council (RGC: N_HKUST625/04).

\section{References}

Agrawal, M., Kumaresh, T.V. and Mercer, G.A. (2001) 'The false promise of mass customization', The Mckinsey Quarterly, Vol. 3, pp.62-71.

Bain \& Company (2005) Management Tools and Trends Survey, Accessed on 9 June, 2007, $\mathrm{http}: / / \mathrm{www}$. bain.com/management_tools/

Cachon, G. (2003) 'Supply chain coordination with contracts', in Graves, S. and de Kok, T. (Eds.): Handbooks in Operations Research and Management Science: Supply Chain Management, North Holland.

Davis, S.M. (1987) Future Perfect, Addison-Wesley Publishing, Reading, MA.

Duray, R. (2002) 'Mass customization origins: mass or custom manufacturing?', International Journal of Operations and Production Management, Vol. 22, No. 3, pp.314-328. 
Feitzinger, E. and Lee, H. (1997) 'Mass customization at HP', Harvard Business Review, January-February, pp.116-121.

Guttman, R.H. and Maes, P. (1999) 'Agent-mediated integrative negotiation for retail electronic commerce', Agent Mediated Electronic Commerce: First International Workshop on Agent Mediated Electronic Trading, AMET-98, Minneapolis, MN, USA.

Hart, C.W. (1995) 'Mass customization: conceptual underpinnings, opportunities and limits', International Journal of Service Industry Management, Vol. 6, No. 2, p.36.

Huffman, C. and Kahn, B.E. (1998) 'Variety for sale: mass customization or mass confusion?', Journal of Retailing, Vol. 74, No. 4, pp.491-513.

Jiao, J. (1998) Design for Mass Customization by Developing Product Family Architecture, $\mathrm{PhD}$ Thesis, Hong Kong University of Science and Technology.

Kilger, C. and Reuter, B. (2005) 'Collaborative planning', Supply Chain Management and Advanced Planning, pp.259-278.

Kotha, S. (1995) 'Mass customization: implementing the emerging paradigm for competitive advantage', Strategic Management Journal, Vol. 16, Special Issue, p.21.

Kotha, S. (1996) 'From mass production to mass customization: the case of the national industrial bicycle company of Japan', European Management Journal, Vol. 14, No. 5, pp.442-450.

Kotler, P. (1989) 'From mass marketing to mass customization', Planning Review Vol. 17, No. 5, p.10.

Lu, S. (2003) Engineering as Collaborative Negotiation: A New Paradigm for Collaborative Engineering, http://wisdom.usc.edu/ecn/index.htm

Magretta, J. (1998) 'The power of virtual integration: an interview with Dell Computer's Michael Dell', Harvard Business Review, Vol. 6, No. 2, pp.73-84.

McCarthy, I.P. (2004) 'Special issue editorial: the what, why and how of mass customization', Production Planning and Control, Vol. 15, No. 4, pp.347-351.

McCutcheon, D.M., Raturi, A.S. and Meredith, J.R. (1994) 'The customization-responsiveness squeeze', Sloan Management Review, Vol. 35, No. 2, pp.89-99.

Monplaisir, L.F. and Salhieh, S.M. (2002) 'Collaborative product design and development: a case study integrating computer-supported collaborative work with quality function development', Collaborative Engineering for Product Design and Development, American Scientific Publishers, pp.125-139.

Piller, F.T., Moeslein, K. and Stotko, C.M. (2004). 'Does mass customization pay? An economic approach to evaluate customer integration', Production Planning and Control, Vol. 15, No. 4, pp.435-444.

Pine, B.J. (1993) Mass Customization: The New Frontier in Business Competition, Harvard Business School Press, Boston, Mass.

Pine, B.J., Victor, B. and Boynton, A.C. (1993) 'Making mass customization work', Harvard Business Review, September-October, pp.108-119.

Sabin, D. and Weigel, R. (1998) 'Product configuration frameworks - a survey', IEEE Intelligent Systems, July-August, pp.42-49.

Salvador, F. and Forza, C. (2004) 'Configuring products to address the customizationresponsiveness squeeze: a survey of management issues and opportunities', International Journal of Production Economics, Vol. 91, No. 3, pp.273-291.

Schwartz, B. (2004) The Paradox of Choice: Why More is Less, ECCO, New York.

Selladurai, R.S. (2004) 'Mass customization in operations management: oxymoron or reality?', OMEGA The International Journal of Management Science, Vol. 32, pp.295-300.

Silveria, G.D., Borenstein, D. and Fogliatto, F.S. (2001) 'Mass customization: literature review and research directions', International Journal of Production Economics, Vol. 72, No. 1, pp.1-13.

Simonson, I. (2005) 'Determinants of customers' responses to customized offers: conceptual framework and research propositions', Journal of Marketing, Vol. 69, No. 1, pp.32-45. 
Spring, M. and Dalrymple, J.F. (2000) 'Product customisation and manufacturing strategy', International Journal of Operations and Production Management, Vol. 20, No. 4, p.441.

Squire, B., Brown, S., Readman, J. and Bessant, J. (2006) 'The impact of mass customization on manufacturing trade-offs', Production and Operations Management, Vol. 15, No. 1, pp.10-21.

Stolze, M. and Strobel, M. (2004) 'Recommending as personalized teaching', Designing Personalized User Experiences in eCommerce, Kluwer Academic Publishers, Norwell, MA, USA.

Toffler, A. (1970) Future Shock, Bantam, London.

Tseng, M.M. and Jiao, J. (1996) 'Design for mass customization', Annals of the CIRP, Vol. 45, No. 1, pp.153-156.

Tseng, M.M. and Piller, F. T. (2003) 'The customer centric enterprise', in Tseng, M. and Piller, F.T. (Eds.): The Customer Centric Enterprise: Advances in Mass Customization and Personalization, Springer, Berlin, Hong Kong.

VICS (2002) CPFR Guidelines v2.0, http://www.vics.org, Accessed on 9 June 2006.

Von Hippel, E.V. (2005) Democratizing Innovation, MIT Press, Cambridge, Mass.

Zipkin, P. (2001) 'The limits of mass customization', Sloan Management Review, Vol. 42, No. 3, pp.81-87.

\section{Note}

${ }^{1}$ Levi's Strauss closed its custom jeans programme (named Original Spin) in 2003; P\&G closed its custom cosmetics programme in 2005. 